Article

\title{
Synthesis of Vanadium Carbide by Mechanical Activation Assisted Carbothermic Reduction
}

\author{
Zaki I. Zaki ${ }^{1,2}$, Mohamed H. El-Sadek ${ }^{2}, *\left(\mathbb{D}\right.$, Heba H. Ali ${ }^{2}$ and Hesham Ahmed $2,3, * \mathbb{C}$ \\ 1 Department of Chemistry, College of Science, Taif University, P.O. Box 11099, Taif 21944, Saudi Arabia; \\ zakimohamed@tu.edu.sa \\ 2 Pyrometallurgy Department, Minerals Technology Division, Central Metallurgical R\&D Institute (CMRDI), \\ P.O. Box 87, Cairo 11865, Egypt; hebahma@cmrdi.sci.eg \\ 3 Department of Civil, Environmental and Natural Resources Engineering, Minerals and Metallurgical \\ Engineering, MiMeR, Luleå University of Technology, 97187 Luleå, Sweden \\ * Correspondence: mhussien@cmrdi.sci.eg (M.H.E.-S.); hesham.ahmed@ltu.se (H.A.); \\ Tel.: +46-7623-646-86 (H.A.)
}

Received: 25 August 2020; Accepted: 1 October 2020; Published: 2 October 2020

check for updates

\begin{abstract}
Vanadium carbide is known, for its hardness and other unique properties, as a refractory material. The synthesis of vanadium carbide is always associated with the utilization of expensive active metals, such as aluminum, calcium and magnesium, as a reducing agent to extract the vanadium metal from its corresponding oxide, followed by carbidization. The carbidization of reduced vanadium requires a complicated process and elevated temperature. Mechanical activation to synthesize vanadium carbide from its corresponding oxide and carbon source represents a promising, straightforward and less energy-intensive route. In the present study, vanadium carbide is synthesized by the carbothermic reduction of a mechanically activated mixture of $\mathrm{V}_{2} \mathrm{O}_{5}$ and carbon black as reducing agents without any additives. The reduction process is monitored by means of thermogravimetric analysis. The reduction products are characterized by $\mathrm{X}$-ray diffraction and field emission scanning electron microscope. It is found that $\mathrm{V}_{8} \mathrm{C}_{7}$ with an average crystallite size of $88 \mathrm{~nm}$ can be synthesized from a $\mathrm{V}_{2} \mathrm{O}_{5}-\mathrm{C}$ mixture after milling for $15 \mathrm{~h}$ and further heating at $1050^{\circ} \mathrm{C}$ for $1 \mathrm{~h}$ in an inert atmosphere.
\end{abstract}

Keywords: mechanical activation; carbothermic reduction; vanadium oxide; carbon black; vanadium carbide

\section{Introduction}

Transition metal carbides have been known for their importance in different fields, such as metallurgy, electronics, refractory applications, cutting tools and catalysts, because of their various unique properties, such as high hardness, high melting point, high temperature strength, high thermal conductivity and high chemical stability [1-6]. Vanadium carbide (VC), an interstitial carbide derived from the (5A) transition metal category, has favorable properties, such as a high melting point $\left(2684^{\circ} \mathrm{C}\right)$, a hardness of 9-9.5 Mohs, an elastic modulus of about $380 \mathrm{GPa}$, chemical stability and high electrical conductivity [7-9]. It has attracted much attention as a material for structures exposed to high temperatures, for surface protection and for wear-resistant parts, especially when used in a corrosive environment. Therefore, it is suitable for several applications, for example, cutting tools and abrasive and anti-wear materials $[10,11]$. It has been commonly used in matrix or coating materials as the reinforcement phase to enhance the wear resistance of metal materials [12]. The uniformly distributed large quantity of spherical or lumpy $\mathrm{VC}$ in high-speed steel enhances its ability to resist abrasive $\mathrm{Al}_{2} \mathrm{O}_{3}$ micro-cutting [13]. 
Traditionally, vanadium carbide is prepared by various methods, such as (i) the low-pressure reaction of vanadium hydride with carbon in a reducing atmosphere at $2000{ }^{\circ} \mathrm{C}$, (ii) the vacuum reaction of elemental vanadium and carbon at a high temperature, (iii) the carbothermic reduction of vanadium trioxide or pentoxide in the presence of active metals (i.e., aluminum, magnesium and calcium) and (iv) the melting of vanadium metal in the presence of carbon. These methods are rather complicated and either energy intensive or rely on costly raw materials $[3,14]$. Recently, other methods have been developed to synthesize vanadium carbide powder, including (i) temperature programmed reactions $[15,16]$, (ii) the aluminothermic reduction of vanadium oxide $[17,18]$, and (iii) the carburization of vanadium oxide with an organic reagent such as cyanamide [19]. Due to their high cost and their limited yield, these methods are still industrially inapplicable.

In the present study, an innovative route to synthesize vanadium carbide by means of the mechanical activation of a mixture of vanadium oxide and carbon is developed. The milling of a metal oxide-carbon mixture is an economical and effective method that would decrease the energy needed for oxide reduction, and could be used in forming the corresponding metal carbide in the presence of sufficient carbon [20-22]. Few studies have investigated the synthesis of vanadium carbide by the mechanical activation of corresponding oxides. Zhang and Li [23] investigated the synthesis of vanadium carbide by ball milling $\mathrm{V}_{2} \mathrm{O}_{5}, \mathrm{Mg}$ and graphite powders at room temperature. They obtained $\mathrm{VC}_{\mathrm{x}}$ after milling the mixture for $36 \mathrm{~h}$ without external heating. The formed $\mathrm{VC}_{\mathrm{x}}$ was then transformed to $\mathrm{V}_{8} \mathrm{C}_{7}$ after annealing at $950{ }^{\circ} \mathrm{C}$. Hossein-Zadeh and Mirzaee [3] synthesized $\mathrm{V}_{8} \mathrm{C}_{7}$ through high-energy ball milling of vanadium pentoxide, calcium and carbon black mixture. After milling, the mixture was then microwave heated. They have concluded that $\mathrm{V}_{8} \mathrm{C}_{7}$ can be prepared after milling for $15 \mathrm{~h}$ and microwave heating at $800{ }^{\circ} \mathrm{C}$ for $10 \mathrm{~min}$. It is worth noting that the starting mixtures in these studies include active metals such as magnesium, calcium and aluminum. Although these methods are simple, the method is still uneconomical due to the high price of active metal powders. This disadvantage opposes the main target of the mechanical activation process. In order to keep this process feasible, the utilization of such active metal powders has to be avoided.

Although the milling or mechanical activation concept is not new in producing alloys or carbides of vanadium from their corresponding oxides, the literature discussing the formation of vanadium carbide from vanadium oxide and carbon with no added active metal powder is missing. Therefore, the present paper focuses on the synthesis of vanadium carbide by mechanical activation of a $\mathrm{V}_{2} \mathrm{O}_{5}-\mathrm{C}$ mixture, followed by heating under controlled conditions. The structure evolution of the produced material is identified using different analytical tools. Moreover, the effects of process parameters such as the mechanical activation condition, the temperature and the time on the synthesis process and the product are also investigated.

\section{Materials and Methods}

\subsection{Materials}

The starting materials used in the present study were i) commercially available powders of $\mathrm{V}_{2} \mathrm{O}_{5}$ (purity of $99 \%$ and mean particle size of $200 \mu \mathrm{m}$ ) purchased from Loba Chemie, Mumbai, India, and ii) high-purity carbon black powder (99\%) with mean particle size $6 \mu \mathrm{m}$, which is used as a reducing agent, purchased from Alexandria carbon black company, Alexandria, Egypt. The particle size distribution was measured using a laser diffraction analysis (BT-2001 laser particle size analyzer, Bettersize instruments, Liaoning, China). The instrument has a particle size measurement range of 0.1 to $1000 \mu \mathrm{m}$. Vanadium pentoxide was mixed thoroughly with excess carbon $(1.5 \times$ stoichiometry) to provide sufficient carbon to ensure the complete reduction of $\mathrm{V}_{2} \mathrm{O}_{5}$ to vanadium carbide according to the following reaction:

$$
\mathrm{V}_{2} \mathrm{O}_{5}+7 \mathrm{C} \rightarrow 2 \mathrm{VC}+5 \mathrm{CO}
$$




\subsection{Procedure}

The $\mathrm{V}_{2} \mathrm{O}_{5}-\mathrm{C}$ mixture was milled for different milling periods ( $\left.5-15 \mathrm{~h}\right)$ in a vertical planetary ball mill with an agate cell containing silicon nitride balls of $20 \mathrm{~mm}$ diameter. A ball powder ratio (BPR) of 10:1 and a rotational speed of $100 \mathrm{rpm}$ were maintained throughout the whole study.

The reduction experiments (synthesis of VC) were carried out in a horizontal tube furnace, a schematic representation of which is depicted in Figure 1. This consisted of an electrically heated horizontal tube furnace with an alumina tube of $100 \mathrm{~cm}$ long and $3 \mathrm{~cm}$ inner diameter. The alumina tube was inserted into the furnace and closed by rubber stoppers with gas inlet-outlet connections. The even temperature zone under this setup was measured to be $\sim 10 \mathrm{~cm}$.

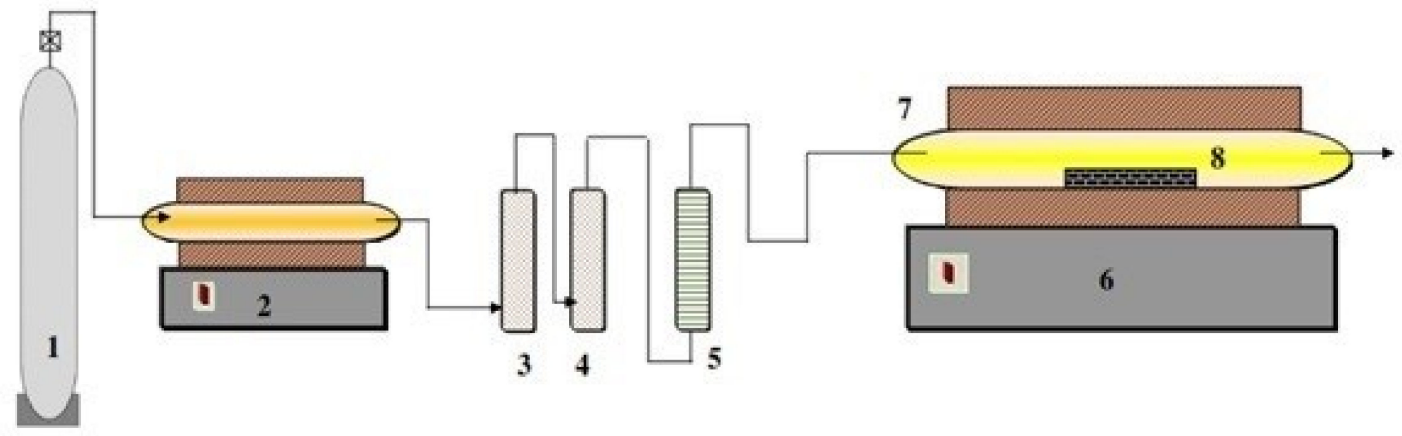

Figure 1. Schematic diagram for the experimental setup for vanadium carbide synthesize, 1 -Argon gas cylinder; 2-Furnace containing copper turnings; 3-Pyrogallol; 4-Silica gel granules; 5-Flow meter; 6-Horizontal tube furnace (maximum temperature $1300{ }^{\circ} \mathrm{C}$ ); 7-Fused alumina tube; 8-Fused alumina boat (sample holder).

Approximately $2 \mathrm{~g}$ of the mechanically activated powder was transferred to a clean fused alumina boat and inserted into the even temperature zone of the furnace. To maintain the oxygen potential in the reaction compartment at the minimum, the residual oxygen, $\mathrm{H}_{2} \mathrm{O}$ and $\mathrm{CO}_{2}$ in the used argon were further removed by passing the gas through heated copper turnings, pyrogallol, and silica gel, respectively. After introducing the sample, the reaction tube was flushed with purified argon to sweep off the residual air in the reaction tube. The sample was then heated at a constant heat rate $\left(10^{\circ} \mathrm{C} / \mathrm{min}\right)$ to the desired temperature $\left(1000-1150{ }^{\circ} \mathrm{C}\right)$ and the reduction process was allowed to continue for a definite period. A continuous flow at $100 \mathrm{~mL} / \mathrm{min}$ of purified argon was maintained throughout the whole thermal cycle. At the end of each experiment, the product sample was rapidly cooled by moving to the gas cooled zone and flushing the sample with purified argon to avoid any oxidation of the reaction product. After cooling down to room temperature, the reaction product was discharged and kept in a desiccator for further characterization.

\subsection{Characterization}

Thermal analysis of the activated mixture was conducted by means of heating the mixture under an inert atmosphere at a constant heating rate of $10{ }^{\circ} \mathrm{C} / \mathrm{min}$, up to $1200{ }^{\circ} \mathrm{C}$ using a Bahr thermal analysis STA 504 instrument with a detection limit of $\pm 0.5 \mathrm{~g}$. The phase compositions of the starting materials as well as the reaction products were analyzed by XRD (XRD, Bruker axs D8, Germany) with $\mathrm{Cu} k \alpha$ radiation $(\lambda=1.5406 \AA)$ and a secondary monochromator in the $2 \theta$ range from $10^{\circ}$ to $80^{\circ}$. Phase identification for the examined samples was carried out using JCPDS (Joint Committee on Powder Diffraction Standards) cards while their morphology was investigated by field emission scanning electron microscope (FESEM, Quanta, FEG 250) in the secondary electron (SE) mode and with an accelerating voltage of $20 \mathrm{kV}$. 


\section{Results and Discussion}

\subsection{Thermogravimetric Analysis}

Figure 2 shows the mass loss (TG) and the first derivative of mass loss (DTG) as a function of the temperature of the mechanically activated $\mathrm{V}_{2} \mathrm{O}_{5}$-carbon mixture. The sample was heated from room temperature up to $1200{ }^{\circ} \mathrm{C}$ at a heating rate $10{ }^{\circ} \mathrm{C} \mathrm{min}^{-1}$ under an argon atmosphere. A net mass loss of $48 \mathrm{wt}$. \% was observed, the mass loss in this case being a result of de-moisturization and the release of reducible oxygen and carbon. TG and DTG curves show three distinguishable different reaction steps, indicated by the slope change over the course of the reaction. The first step was a gradual mass loss with a very slow rate, which started from $100{ }^{\circ} \mathrm{C}$ and proceeded up to $310{ }^{\circ} \mathrm{C}$ with a mass loss of $5 \mathrm{wt}$. \%. This initial slow mass loss rate can be attributed to the desorption of adsorbed moisture during the mechanical activation process. The second mass loss step started from $310^{\circ} \mathrm{C}$ and continued to $810^{\circ} \mathrm{C}$, with a mass loss value of $15 \mathrm{wt}$. \% which can be related to the slow solid-solid reaction between carbon particles and $\mathrm{V}_{2} \mathrm{O}_{5}$ to produce $\mathrm{VO}_{2}$. This mass loss value matches nicely with the theoretical weight loss when $\mathrm{V}_{2} \mathrm{O}_{5}$ is reduced to $\mathrm{VO}_{2}$ by carbon (14.4 wt. \%). The mass loss appeared to level-off between $810^{\circ} \mathrm{C}$ and $950^{\circ} \mathrm{C}$, and then started to increase again above $950^{\circ} \mathrm{C}$. This behavior could be attributed to the effect of the formed $\mathrm{VO}_{2}$, which produced a thick layer hindering the diffusion of carbon monoxide gas away from the reaction site and consequently retarded the reaction progress. Increasing the temperature resulted in a significantly increased mass loss rate until it approached 28 wt. $\%$ mass loss at $1150^{\circ} \mathrm{C}$, which is due to the continuation of the reduction of $\mathrm{VO}_{2}$ to $\mathrm{VC}$.

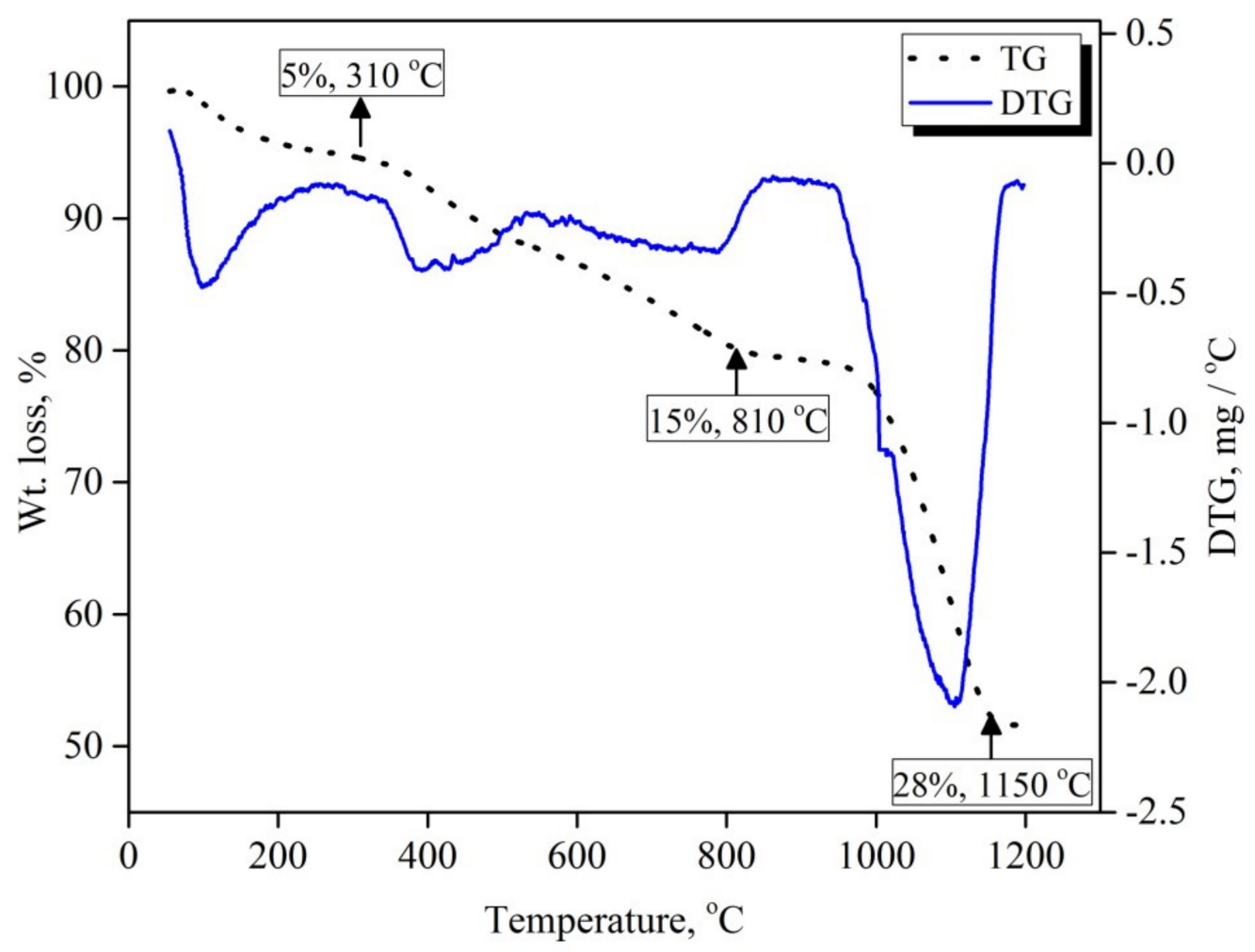

Figure 2. TGA-DTG curves of $15 \mathrm{hr}$ mechanically activated $\mathrm{V}_{2} \mathrm{O}_{5}$-carbon black mixture.

\subsection{Effect of Reduction Temperature}

Figure 3 displays the XRD patterns of the mechanically activated $\mathrm{V}_{2} \mathrm{O}_{5}-\mathrm{C}$ mixture and its carbidization products at different temperatures. It is obvious that the temperature has a considerable effect on the formation of vanadium carbide. The XRD patterns of the mechanically activated $\mathrm{V}_{2} \mathrm{O}_{5}-\mathrm{C}$ 
mixture prior to heat treatment show only $\mathrm{V}_{2} \mathrm{O}_{5}$ peaks, while no peaks corresponding to carbon could be detected. The absence of carbon peaks can be attributed to the amorphization of carbon due to mechanical activation. Moreover, the only observed difference between the starting vanadium pentoxide patterns and the mechanically activated $\mathrm{V}_{2} \mathrm{O}_{5}$ in the mixture was the broadening of peaks, which can be explained by the reduction in the mean particle size of the mixture which is, in turn, a result of milling during the extended duration. Furthermore, the reduction in mechanically activated mixture at $100{ }^{\circ} \mathrm{C}$ gave rise to the formation of $\mathrm{V}_{2} \mathrm{O}_{3}$ phase, with small amounts of vanadium carbide, and traces of $\mathrm{V} \mathrm{VO}_{2}$ phase. By raising the temperature up to $1050{ }^{\circ} \mathrm{C}$, the intensity of $\mathrm{V}_{2} \mathrm{O}_{3}$ decreases sharply and, in parallel, high intensity peaks of vanadium carbide were observed without the presence of any intermediates of other vanadium oxides. So, the XRD patterns of partially reacted mixtures suggest that during the reduction process, the powders undergo the following phase transformations: (i) $\mathrm{V}_{2} \mathrm{O}_{5}$ transforms to $\mathrm{V}_{2} \mathrm{O}_{3}$ and a minor amount of $\mathrm{VO}_{2}$, and (ii) the vanadium lower oxide transform to the corresponding carbide $\left(\mathrm{V}_{8} \mathrm{C}_{7}\right)$. No diffraction line of $\mathrm{VO}$ phase is observed in the diffraction pattern, which confirms that the phase transformation does not obtain from $\mathrm{V}_{2} \mathrm{O}_{3}$ to VO. A further increase in reduction temperature to $1100{ }^{\circ} \mathrm{C}$ has no detectable effect on the formed phase, unless one increases the intensity of the formed vanadium carbide phase due to crystal growth. The average crystallite size of the formed vanadium carbide increases from $60 \mathrm{~nm}$ at $1000{ }^{\circ} \mathrm{C}$ to $88 \mathrm{~nm}$ at $1100{ }^{\circ} \mathrm{C}$.

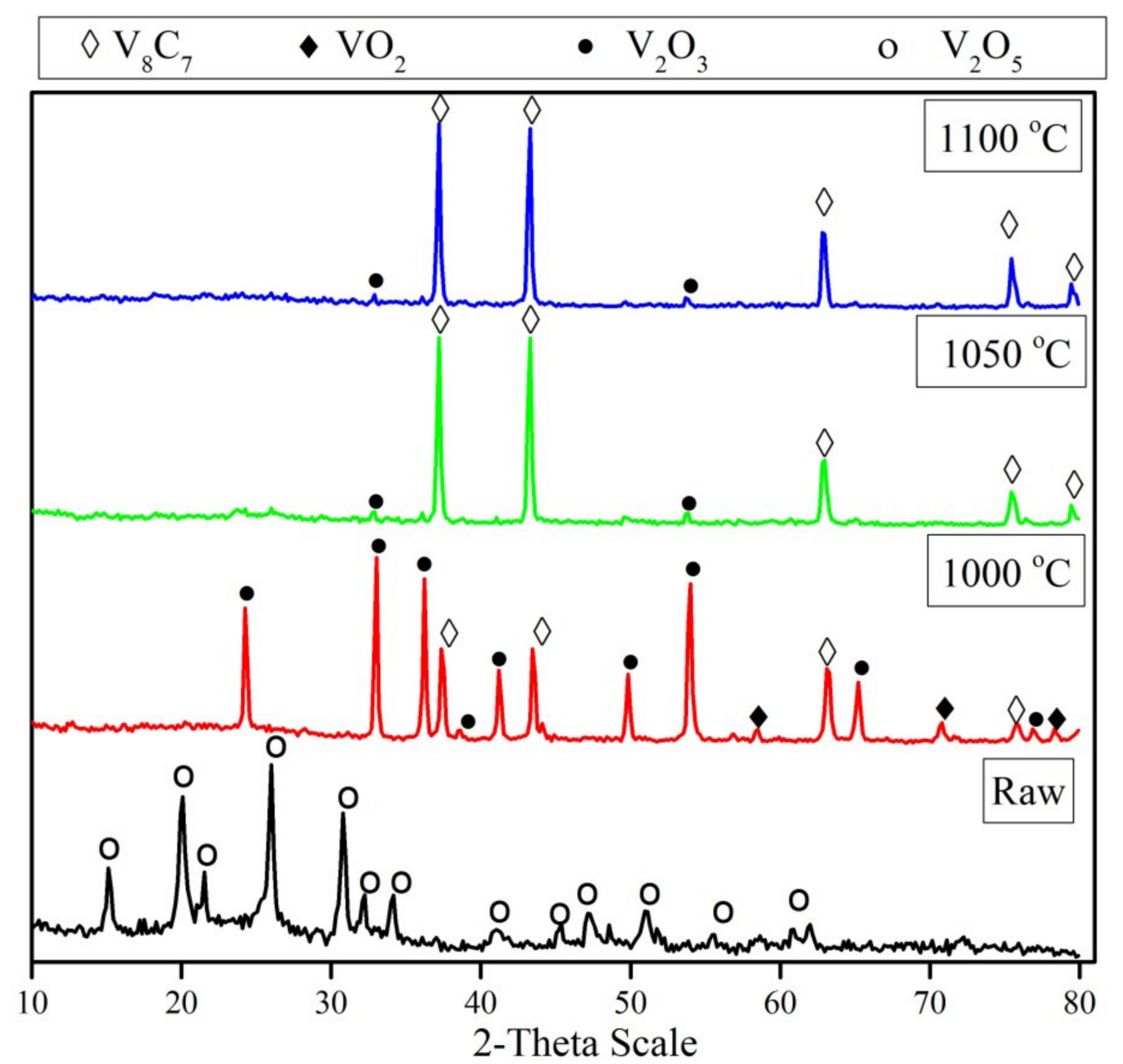

Figure 3. XRD patterns of un-milled, and reduction products of $15 \mathrm{~h}$ milled, $\mathrm{V}_{2} \mathrm{O}_{5}-\mathrm{C}$ mixture at temperature range $1000-1100{ }^{\circ} \mathrm{C}$ for $1 \mathrm{~h}$. 


\subsection{Effect of Reduction Time}

The effect of the reduction time of the $\mathrm{V}_{2} \mathrm{O}_{5}-\mathrm{C}$ mixture (milled for $15 \mathrm{~h}$ ) was investigated at $1050{ }^{\circ} \mathrm{C}$. Figure 4 presents the XRD patterns of phases formed during the carbidization process of the $\mathrm{V}_{2} \mathrm{O}_{5}-\mathrm{C}$ mixture at $1050{ }^{\circ} \mathrm{C}$. It can be noticed that the carbide formation increases along with increasing the reduction time from $15 \mathrm{~min}$ up to $30 \mathrm{~min}$. A further increase in reduction time had no significant effect on the formation of vanadium carbide, unless one increases the crystallite size from $80 \mathrm{~nm}$ at $15 \mathrm{~min}$ to $88 \mathrm{~nm}$ at $60 \mathrm{~min}$.

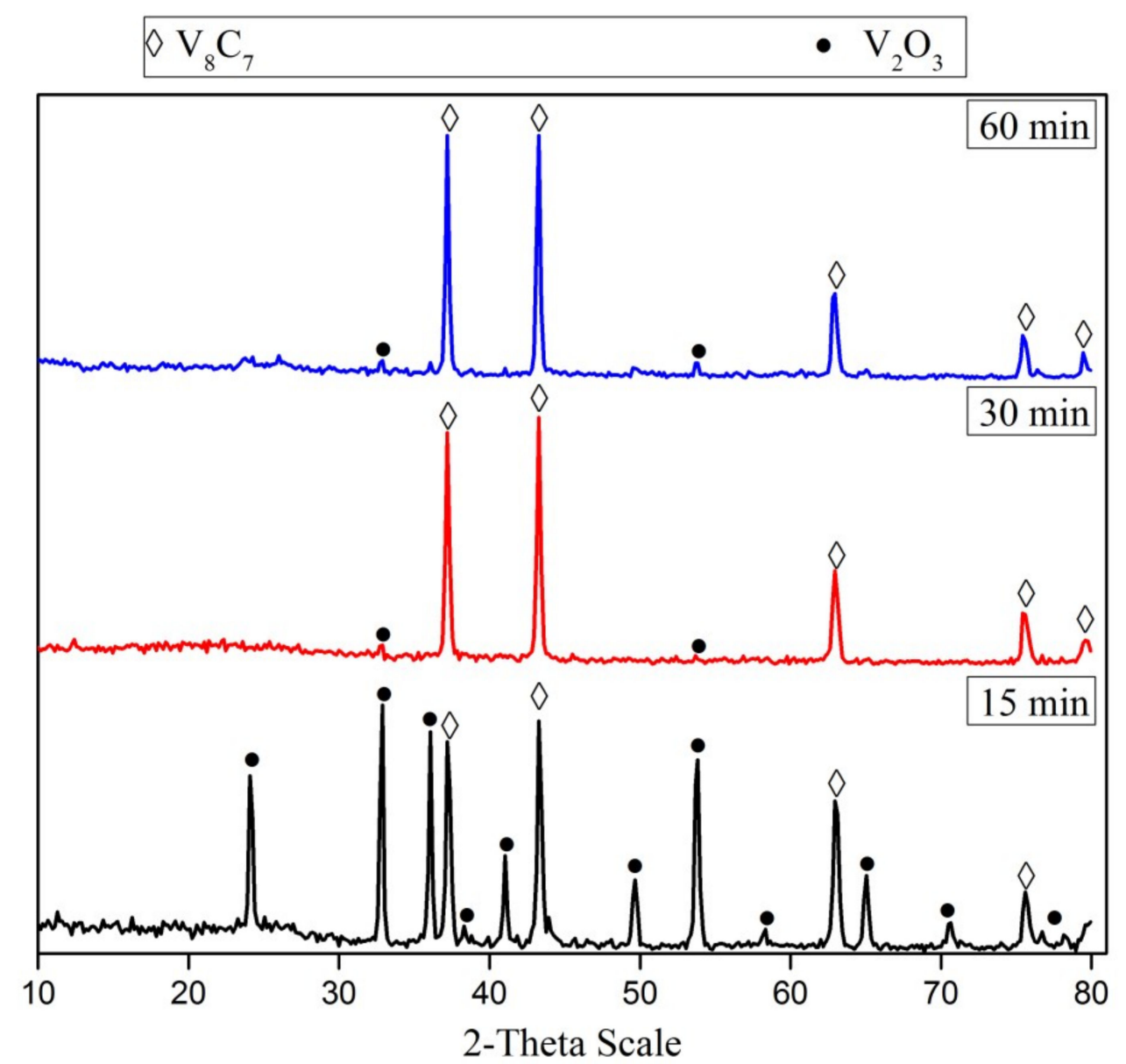

Figure 4. XRD patterns of $15 \mathrm{~h}$ mechanically activated $\mathrm{V}_{2} \mathrm{O}_{5}-\mathrm{C}$ mixture reduction products at $1050{ }^{\circ} \mathrm{C}$ for different reduction periods.

\subsection{Effect of Mechanical Activation}

The un-milled and milled powder mixtures during different periods were heated up to $1050{ }^{\circ} \mathrm{C}$ for $1 \mathrm{~h}$ in an inert atmosphere. The XRD patterns of the reaction products are shown in Figure 5. The XRD pattern of the un-milled mixture after the reaction shows the presence of strong $\mathrm{V}_{2} \mathrm{O}_{3}$ peaks and traces of vanadium carbide $\left(\mathrm{V}_{8} \mathrm{C}_{7}\right)$. On the other hand, it is obvious that mechanical activation has a significant effect on the reduction and carbidization of $\mathrm{V}_{2} \mathrm{O}_{5}$. Comparing the XRD patterns of milled mixtures during different periods (5-15 h), it can be observed that the intensity of $\mathrm{V}_{8} \mathrm{C}_{7}$ increases along with increasing the milling periods. The intensity of the $\mathrm{V}_{2} \mathrm{O}_{3}$ peaks decreases with increased milling time until it disappears in the reaction products of the mixture milled for $15 \mathrm{~h}$. In all cases, no lower vanadium oxides (rather than $\mathrm{V}_{2} \mathrm{O}_{3}$ ) were detected, irrespective of milling duration. The average crystallite size of vanadium carbide prepared from a $5 \mathrm{~h}$ milled mixture $(70 \mathrm{~nm})$ is lower than that of the $15 \mathrm{~h}$ milled mixture $(88 \mathrm{~nm})$. 


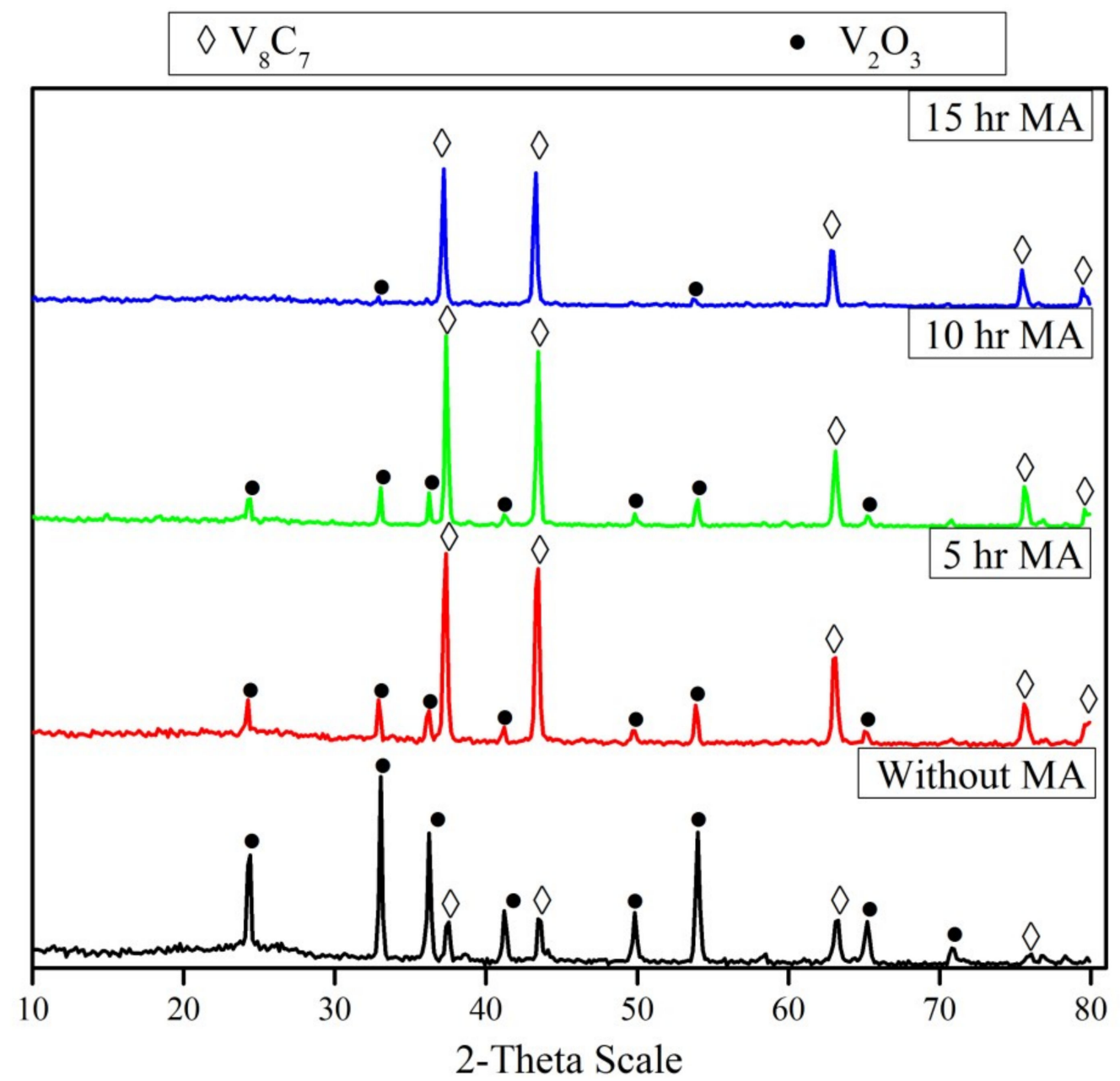

Figure 5. XRD patterns of reduction products of un-milled and milled $\mathrm{V}_{2} \mathrm{O}_{5}-\mathrm{C}$ mixture at different periods (5-15 h) after reduction at $1050{ }^{\circ} \mathrm{C}$ for $1 \mathrm{~h}$.

\subsection{Microstructure Characterization}

Figure 6 shows the FESEM micrographs of the $15 \mathrm{~h}$ mechanically activated mixture (Figure 6a) at $30,000 \times$ magnification, with the scale bar representing $3 \mu \mathrm{m}$, and its reduction product obtained at $1050{ }^{\circ} \mathrm{C}$ for $1 \mathrm{~h}$ (Figure $6 \mathrm{~b}$ ) at $120,000 \times$ magnification, with the scale bar representing $500 \mathrm{~nm}$. Before the carbidization process (after milling for $15 \mathrm{~h}$ ), the SEM micrograph (Figure 6a) shows the well-mixed fine particles of $\mathrm{V}_{2} \mathrm{O}_{5}$ and carbon black where the average particle size of the $\mathrm{V}_{2} \mathrm{O}_{5}-\mathrm{C}$ clusters was below $3 \mu \mathrm{m}$, which indicates high surface area, and thus increases the interfacial surface area between the reactants while shortening the diffusion paths. These enhancements, in addition to the created stresses due to friction and collision during milling, lead to lowering the carbidization temperature and improving the reaction kinetics. The morphology of the sample synthesized at $1050{ }^{\circ} \mathrm{C}$ for $1 \mathrm{~h}$ (Figure 6b) shows particles of a nanometric size (less than $500 \mathrm{~nm}$ ), and agglomerations exist in cubic or spheroid shapes and consist of multiple particles. 

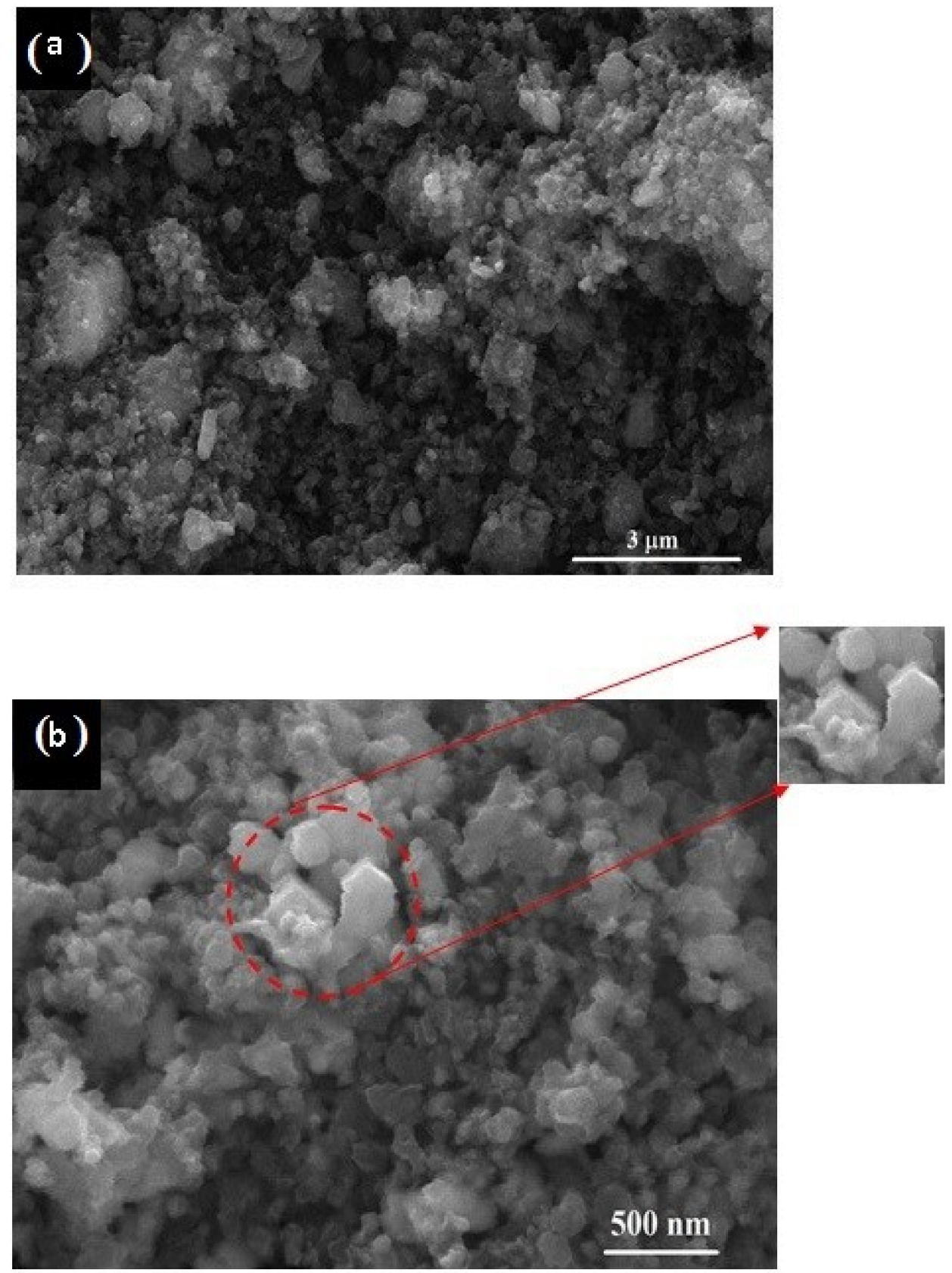

Figure 6. SEM micrograph of $15 \mathrm{~h}$ milled $\mathrm{V}_{2} \mathrm{O}_{5}-\mathrm{C}$ mixture (a) and its reduction product at $1050{ }^{\circ} \mathrm{C}$ for $1 \mathrm{~h}(\mathbf{b})$.

\subsection{Thermodynamic Calculation}

To further understand the reaction mechanism and explain the experimental results, a set of calculations was conducted using the Equilibria module in the thermodynamic software FactSage $7.3^{\mathrm{TM}}$, developed by GTT (Herzogenrath, Germany) and CRCT (Quebec, QC, CA) [24]. In the calculations, an open system configuration was considered. In the open configuration, the product gas is continuously taken away from the system and is not considered in the following calculations. The data bases used were FT oxide, FT misc and SGPS (oxide, miscellaneous, pure substances databases respectively). The obtained calculations are given in Figure 7. 


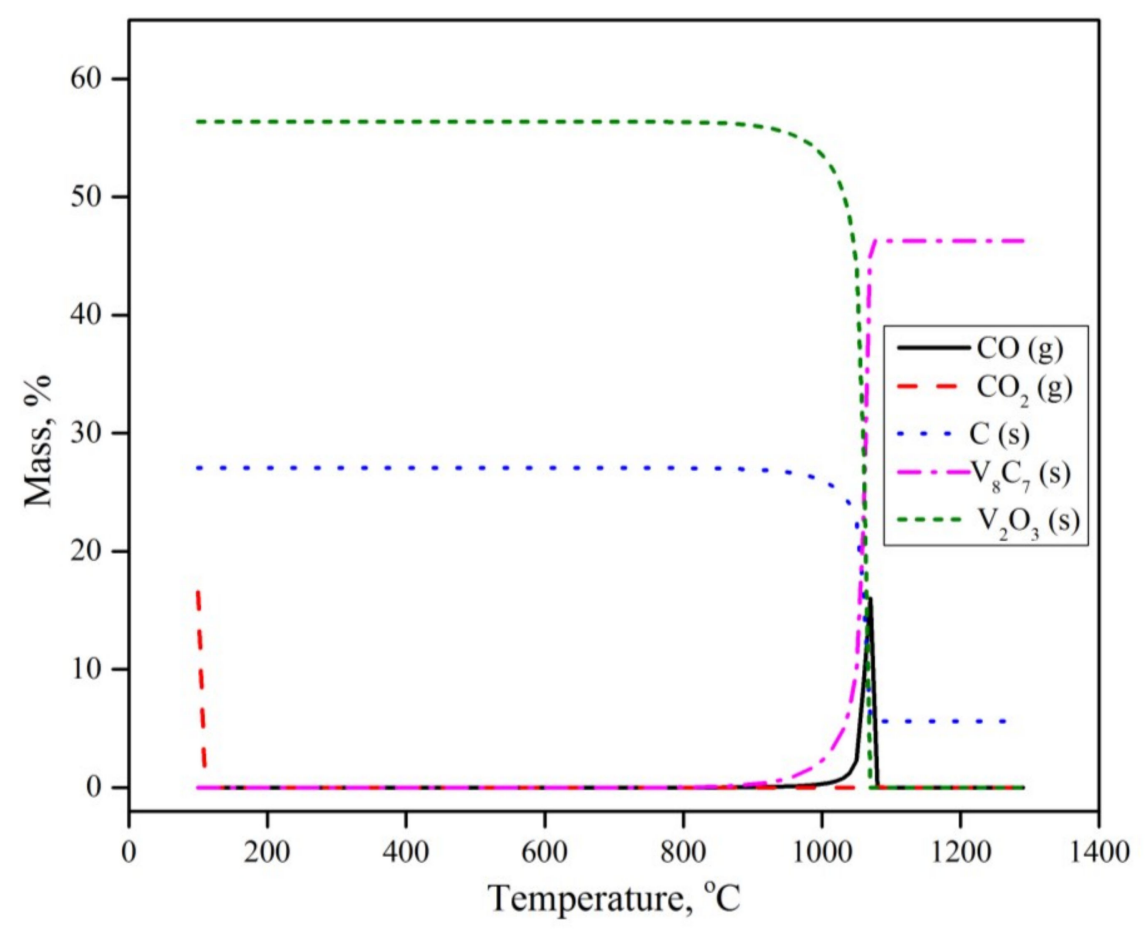

Figure 7. Thermodynamic calculations using FactSage.

The equilibrium calculations revealed that in the presence of carbon and argon as a carrier gas, $\mathrm{V}_{2} \mathrm{O}_{5}$ is not thermodynamically stable, and will dissociate into $\mathrm{V}_{2} \mathrm{O}_{3}$ and $\mathrm{O}_{2}$ in the ambient temperature and pressure. $\mathrm{O}_{2}$ then reacts with solid $\mathrm{C}$ and forms $\mathrm{CO}_{2}$, according to Equation (2)

$$
\mathrm{V}_{2} \mathrm{O}_{5}(\mathrm{~s})+\mathrm{C}(\mathrm{s}) \rightarrow \mathrm{V}_{2} \mathrm{O}_{3}(\mathrm{~s})+\mathrm{CO}_{2}(\mathrm{~g})
$$

This observation does not agree with either the thermogravimetric or XRD results. Such a contradiction indicates that the early transformation of vanadium pentoxide is limited by reaction kinetics rather than equilibrium. The thermogravimetric results showed that $\mathrm{V}_{2} \mathrm{O}_{5}$ reduction to $\mathrm{V}_{2} \mathrm{O}_{3}$ occurs under the present conditions, in the temperature range of 300 to $800{ }^{\circ} \mathrm{C}$. According to the present equilibrium calculations, $\mathrm{CO}_{2}$ will leave the system without any further reaction. $\mathrm{V}_{2} \mathrm{O}_{3}$ is the only thermodynamically stable vanadium oxide phase throughout the experiment, until temperatures exceed $900{ }^{\circ} \mathrm{C}$. Above $900{ }^{\circ} \mathrm{C}, \mathrm{V}_{2} \mathrm{O}_{3}$ transforms into $\mathrm{V}_{8} \mathrm{C}_{7}$ with no intermediates of other oxide or metallic phases. This observation agrees nicely with the experimental results.

It is worth mentioning that some minor XRD peaks corresponding to $\mathrm{VO}_{2}$ were observed, while the equilibrium calculations showed no sign of its formation. This can be explained by the fact that under a specific condition of oxygen partial pressure and temperature, the solid solutions of $\mathrm{VO}_{2}$ and $\mathrm{V}_{2} \mathrm{O}_{3}$ might coexist. However, this phase is not thermodynamically stable under the present experimental conditions.

\section{Conclusions}

In the present study, we attempted to synthesize vanadium carbide from its corresponding oxide and carbon as the sole reducing and carbidizing agent, respectively. The following points can be concluded:

1. Under the conventional conditions of the carbothermic reduction of vanadium oxide, a very small portion of the oxide can be converted to carbide, resulting in a very poor yield.

2. The mechanical activation-assisted carbothermic reduction of vanadium oxide, on the other hand, gives promising results, with a very high yield of about $95 \%$. 
3. The effects of reaction parameters like temperature, reduction duration and mechanical activation duration on the formation of vanadium carbide and the final product's properties were investigated, and the optimum conditions were identified.

4. $\quad \mathrm{V}_{8} \mathrm{C}_{7}$ nanoparticles with a crystallite size of $88 \mathrm{~nm}$ were prepared from a mechanically activated $\mathrm{V}_{2} \mathrm{O}_{5}-\mathrm{C}$ mixture after milling for $15 \mathrm{~h}$ and further heating at $1050{ }^{\circ} \mathrm{C}$ for $1 \mathrm{~h}$.

5. The experimental results at and above $950{ }^{\circ} \mathrm{C}$ were successfully explained by equilibrium calculations. At lower temperatures, the reactions were kinetically limited.

Author Contributions: Conceptualization, Z.I.Z., M.H.E.-S., H.H.A. and H.A.; writing-review and editing, Z.I.Z., M.H.E.-S., H.H.A. and H.A.; planning, performing experiments, evaluation and writing-original draft, M.H.E.-S.; thermodynamic calculations, H.A. All authors have read and agreed to the published version of the manuscript.

Funding: This research received no external funding.

Acknowledgments: The authors gratefully acknowledged Taif University Researchers Supporting Project (TURSP-2042) Taif University, Taif, Saudi Arabia; Center of Advanced Mining and Metallurgy $\left(\mathrm{CAMM}^{2}\right)$ at Luleå University of Technology, Luleå, Sweden; and Central Metallurgical Research and Development Institute (CMRDI), Cairo.

Conflicts of Interest: The authors declare no conflict of interest.

\section{References}

1. Hossein-Zadeh, M.; Razavi, M.; Safa, M.; Abdollahi, A.; Mirzaee, O. Synthesis and structural evolution of vanadium carbide in nano scale during mechanical alloying. J. King Saud Univ. Eng. Sci. 2016, 28, 207-212. [CrossRef]

2. Ma, J.; Wu, M.; Du, Y.; Chen, S.; Ye, J.; Jin, L. Low temperature synthesis of vanadium carbide (VC). Mater. Lett. 2009, 63, 905-907. [CrossRef]

3. Hossein-Zadeh, M.; Mirzaee, O. Synthesis and characterization of V8C7 nanocrystalline powder by heating milled mixture of V2O5, C and Ca via mechanochemical activation. Adv. Powder Technol. 2014, 25, 978-982. [CrossRef]

4. Mahajan, M.; Singh, K.; Pandey, O.P. Single step synthesis of nano vanadium carbide-V8C7 phase. Int. J. Refract. Met. Hard Mater. 2013, 36, 106-110. [CrossRef]

5. Kurlov, A.S.; Gusev, A.I. Preparation and microstructure of VC0.875 nanopowder. Inorg. Mater. 2013, 49, 347-354. [CrossRef]

6. Chen, Y.; Zhang, H.; Ye, H.; Ma, J. A simple and novel route to synthesize nano-vanadium carbide using magnesium powders, vanadium pentoxide and different carbon source. Int. J. Refract. Met. Hard Mater. 2011, 29, 528-531. [CrossRef]

7. Bauer, G.; Güther, V.; Hess, H.; Otto, A.; Roidl, O.; Roller, H.; Sattelberger, S. Vanadium and Vanadium Compounds. In Ullmann's Encyclopedia of Industrial Chemistry; American Cancer Society: New York, NY, USA, 2017; pp. 1-22.

8. Matsushita, J.-I.; Nakayama, T. Oxidation behavior of vanadium carbide powder. J. Adv. Sci. 1998, 10, 97-99. [CrossRef]

9. Hannink, R.H.J.; Murray, M.J. Elastic moduli measurements of some cubic transition metal carbides and alloyed carbides. J. Mater. Sci. 1974, 9, 223-228. [CrossRef]

10. Kato, C.; Bailey, J.A. Wear Characteristics of a Woodworking Knife with a Vanadium Carbide Coating only on the Clearance Surface (Back Surface). Key Eng. Mater. 1997, 138, 479-520. [CrossRef]

11. Borisova, A.; Borisov, Y.; Shavlovsky, E.; Mits, I.; Castermans, L.; Jongbloed, R. Vanadium carbide coatings: deposition process and properties. 15th International Plansee Seminar: Powder Metallurgical High Performance Materials, Reutte, Austria, 15-17 May 2001; Wildner, H., Ed.; Volume 2: P/M Hard Materials. p. 896.

12. Krajewski, A.; D'Alessio, L.; De Maria, G. Physiso-Chemical and Thermophysical Properties of Cubic Binary Carbides. Cryst. Res. Technol. 1998, 33, 341-374. [CrossRef]

13. Wei, S.; Zhu, J.; Xu, L. Research on wear resistance of high speed steel with high vanadium content. Mater. Sci. Eng. A 2005, 404, 138-145. [CrossRef]

14. Gupta, C.K.; Krishnamurthy, N. Extractive Metallurgy of Vanadium; Elsevier: Amsterdam, The Netherlands, 1992. 
15. Claridge, J.B.; York, A.P.E.; Brungs, A.J.; Green, M.L.H. Study of the Temperature-Programmed Reaction Synthesis of Early Transition Metal Carbide and Nitride Catalyst Materials from Oxide Precursors. Chem. Mater. 2000, 12, 132-142. [CrossRef]

16. Kapoor, R.; Oyama, S. Synthesis of Vanadium Carbide by Temperature Programmed Reaction. J. Solid State Chem. 1995, 120, 320-326. [CrossRef]

17. Hossein-Zadeh, M.; Tebyani, F.; Cherati, J.Y.; Mirzaee, O. Mechanochemical Carboaluminothermic Reduction of V2O5 to Produce VC-A12O3 Nanocomposite. J. Teknol. 2012, 59. [CrossRef]

18. Venugopalan, R.; Sathiyamoorthy, D. Investigation through factorial design on novel method of preparing vanadium carbide using carbon during aluminothermic reduction. J. Mater. Process. Technol. 2006, 176, 133-139. [CrossRef]

19. Li, P.; Lei, M.; Tang, W. Route to transition metal carbide nanoparticles through cyanamide and metal oxides. Mater. Res. Bull. 2008, 43, 3621-3626. [CrossRef]

20. El-Eskandarany, M.S. Mechanical Alloying: For Fabrication of Advanced Engineering Materials; University Press of Mississippi: Jackson, MS, USA, 2013.

21. Hoseinpur, A.; Khaki, J.V.; Marashi, M.S. Mechanochemical synthesis of tungsten carbide nano particles by using WO3/Zn/C powder mixture. Mater. Res. Bull. 2013, 48, 399-403. [CrossRef]

22. Suryanarayana, C. Mechanical alloying and milling. Prog. Mater. Sci. 2001, 46,1-184. [CrossRef]

23. Zhang, B.; Li, Z. Synthesis of vanadium carbide by mechanical alloying. J. Alloy. Compd. 2005, 392, $183-186$. [CrossRef]

24. Bale, C.; Bélisle, E.; Chartrand, P.; Decterov, S.; Eriksson, G.; Gheribi, A.; Hack, K.; Jung, I.-H.; Kang, Y.-B.; Melançon, J.; et al. FactSage thermochemical software and databases, 2010-2016. Calphad 2016, 54, 35-53. [CrossRef]

(C) 2020 by the authors. Licensee MDPI, Basel, Switzerland. This article is an open access article distributed under the terms and conditions of the Creative Commons Attribution (CC BY) license (http://creativecommons.org/licenses/by/4.0/). 